\title{
Determination of the Relationship between Healthy Lifestyle Behaviors, Physical Fitness, and Risk Factors of Coronary Heart Diseases in University Students
}

\author{
Ali Ozkan ${ }^{1,2}$, Mutlu Turkmen ${ }^{1,3, *} \mathbb{D}$, Taner Bozkus ${ }^{1}$, Murat Kul ${ }^{1}$, Recep Soslu ${ }^{4}$, \\ Fatih Yasarturk ${ }^{1}$, Recep Aydin ${ }^{1}$ and Umit $\mathrm{Oz}^{1}$ \\ 1 School of Physical Education and Sports, Bartin University, 74110 Bartın, Turkey; \\ ali_ozkan1@hotmail.com (A.O.); tanerbozkus@yahoo.com (T.B.); muratkul61@gmail.com (M.K.); \\ fatihyasarturk@gmail.com (F.Y.); g.recep.aydin@gmail.com (R.A.); ozumut06@hotmail.com (U.O.) \\ 2 Physical Education Research and Application Center, Bartin University, 74100 Bartin, Turkey \\ 3 Turkish Bocce Bowling and Darts Federation, 74100 Ankara, Turkey \\ 4 School of Physical Education and Sports, Karamanoğlu Mehmetbey University, 70000 Karaman, Turkey; \\ recepsosli@gmail.com \\ * Correspondence: mutluturkmen@bartin.edu.tr; Tel.: +90-532-505-7565
}

Received: 10 April 2018; Accepted: 15 April 2018; Published: 17 April 2018

\begin{abstract}
The purpose of the present study was to determine the relationship between healthy lifestyle behaviors, physical fitness, and coronary risk factors in university students. 320 male and female $\left(\mathrm{n}_{\mathrm{m}}: 171 ; \mathrm{n}_{\mathrm{f}}: 149\right.$, respectively) students from a university participated in this study voluntarily. For the determination of body composition and Body Mass Indexes (BMI), subjects' height, body weight, and skinfold thickness were taken and body fat percentage (\% fat) was determined. Healthy lifestyle behaviors were determined using the healthy lifestyle behaviors questionnaire. Indicators of physical fitness included flexibility (sit-up) (F), muscle strength and endurance (isometric knee (KS), back strength (BS) and a total of shuttle (TS), sprint performance, BMI, and body fat percentage (\% fat). Coronary heart disease risk factors included mean arterial blood pressure (systolic (SBP) and diastolic (DBP)), fasting blood levels of triglycerides (TG), total cholesterol (TC), hematocrit (HCT), and hemoglobin (HGB). Results indicated subjects have normal body mass index, body fat percentage, SBP, DBP, TG, TCF, BS, and KS. The results of the Pearson Product Moment Correlation Analysis, indicated that SBP, DBP, TG, TCF, BS, and KS for male and female was significantly correlated with flexibility (sit-up) (F), muscle strength and endurance (isometric knee (KS), back strength (BS) and total of shuttle (TS)), sprint performance. $(p<0.01 ; p<0.05)$, In conclusion, the findings of the present study indicated that physical fitness and healthy lifestyle behaviors play a determinant role in coronary heart disease risk factors for male and female students from a university.
\end{abstract}

Keywords: coronary heart disease risk factors; healthy lifestyle behaviors; physical fitness

\section{Introduction}

Coronary heart disease (CHD) continues to be a leading cause of morbidity and mortality among adults in Europe and North America [1]. For example, CHD is responsible for 29,500 deaths in Australia annually. Ninety-there percent of women and $80 \%$ of men who die as a result of CHD are over the age of 65 [2]. Similar statistics are reported in Canada [3], the United States, the United Kingdom [4], and Turkey [5]. Risk factors have included blood pressure, cigarette smoking, cholesterol (TC), low-density cholesterol (LDL-C), high-density cholesterol (HDL-C), and diabetes. Two-four factors such as obesity, left ventricular hypertrophy, family history of premature CHD, and physically inactive [3] have also been considered in defining CHD risk [1] and increased physical activity leads to greater cardiorespiratory fitness, decreased blood pressure and body weight and increased HDL-C, 
all of which lead to a more favorable CHD risk profile [6]. The study of adaptive functional changes of the human body induced by physical effort to optimise the physical wellness and to combat the metabolic, circulation, and respiratory diseases are trending in the interdisciplinary scientific research from medicine and physical activity [7-9].

A recent meta-analysis showed a significant protective effect of physical activity and physical health-related fitness on CHD $[10,11]$. Physical inactivity is associated with an increased risk of a wide variety of diseases like cardiovascular diseases, hypertension, type 2 diabetes, obesity, and depression. It has been stated the above-mentioned diseases which are associated with physical inactivity seldom manifest themselves before adulthood, however, promotion of physical activity may be important as physical inactivity may also predispose to a future sedentary lifestyle and hence have an increased risk for these diseases. Several reviews have indicated that the associations among physical activity fitness and CHD risk factors in youth have not been conclusively delineated [3,11-13]. A number of more recent studies have examined these associations but results remain equivocal. For example, in the cardiovascular risk in young Finns study ( 9 to 24 years age), active males had lower TG and higher HDL-C level than inactive males, while active females had lower TG levels than inactive females controlling for pubertal status [12]. For instance, Heggebo et al. [14] reported that the results in terms of the anthropometrical measures, diastolic and systolic blood pressure were the major factors explaining the cardiorespiratory fitness. Hence, the purpose of the present study was to determine the relationship between healthy lifestyle behaviors, physical fitness and coronary risk factors in university students.

\section{Materials and Methods}

\subsection{Subjects}

Three hundred and twenty male and female $\left(\mathrm{n}_{\mathrm{m}}: 171 ; \mathrm{n}_{\mathrm{f}}: 149\right.$, respectively) students attending to Bartin University in Turkey participated in this study voluntarily during the spring term of 2015-2016 education year. The arithmetic averages (and standard deviations) of age, height, body weight, and body fat of the subjects were calculated 20.89 (2.01) years, $168.04(14.7) \mathrm{cm}, 67.2(16.25) \mathrm{kg}$, and 20.66 (7.01), respectively. All subjects gave their informed consent for inclusion before they participated in the study. The study was conducted in accordance with the Declaration of Helsinki and this study was approved by Bartin University Institutional Review Board, Ethics Committee and supported by Bartin University Scientific Research Projects Commission (Project No: 2016-SOS-A-006).

\subsection{Anthropometric Measurements}

Body height $(\mathrm{cm})$, body mass $(\mathrm{kg})$, and percentage of body fat $(\mathrm{PBF})$ measurements were taken for each subject. The body height of the university students were measured by a stadiometer with an accuracy of $\pm 1 \mathrm{~cm}$ (SECA, Hamburg, Germany), and while electronic scales (Tanita BC 418, Tokyo, Japan) accurate to within $0.1 \mathrm{~kg}$ were used to measure body mass and percentage of body fat [15]. Skinfold thickness was measured with a Holtain skinfold caliper (Holtain, Crymych, UK) which applied a pressure of $10 \mathrm{~g} / \mathrm{mm}^{2}$ with an accuracy of $\pm 2 \mathrm{~mm}$. Gulick anthropometric tape (Holtain, UK) with an accuracy of $\pm 1 \mathrm{~mm}$ was used to measure the circumference of extremities. Diametric measurements were determined by Harpenden calipers (Holtain, UK) with an accuracy of $\pm 1 \mathrm{~mm}$.

\subsection{Health-Promoting Lifestyle Profile Scale}

Health-promoting Lifestyle Profile Scale was used for collecting data on their health behaviors. The scale was developed by Walker et al. [16]. It is composed of 48 items and 6 subscales and consists of questions about health-promoting behaviors. The subscales were on self-actualization (SA), health responsibility (HR), exercise (E), nutrition (N), interpersonal support (IS), and stress management (SM). The total score reflects the healthy lifestyle behavior. Four more items were added to the scale, and now the scale is composed of 52 items [16]. Each respondent was asked to rate each item on Likerts' 1 to 4 response scale where 1 corresponds to never, 2 sometimes, 3 often, 4 regularly. Alpha coefficient reliability of the scale was 0.92 , and alpha coefficient reliability of the subscales varied from 
0.70 to 0.90 . The reliability of the scale for Turkish population was tested by Esin [17] and Akça [18]. Alpha coefficient reliability of the scale was 0.91 in Esin's study and 0.90 in Akça's study.

\subsection{Flexibility Measurement}

Flexibility was evaluated by the sit and reach test which is the most common flexibility test used in health-related fitness test batteries. The subjects sat with their feet approximately hip-width against the testing box. They kept their knees extended and placed the right hand over the left, and slowly reached forward as far as they could by sliding their hands along the measuring board. Reaches short of the toes were recorded as negative forward reach scores, and reaches beyond the toes were recorded as positive forward reach scores in centimeter to the nearest $0.5 \mathrm{~cm}$ using the scale on the box [19].

\subsection{Strength Measurement}

Isometric Dynamometer was used for the determination of knee, back, grip strength. Muscular strength was assessed using a Takei strength dynamometer (Takei Scientific Instruments, Tokyo, Japan).

\subsection{Coronary Heart Disease Risk Factors}

\subsubsection{Blood Pressure}

Systolic and diastolic blood pressures were measured with a sphygmomanometer (Erka perfect Aneroid, Germany) following the recommendations of the American Heart Association.

\subsubsection{Lipids and Lipoproteins}

All venous and capillary blood lipid concentrations were determined in the morning after an overnight fasting period of at least eight hours. In each subject, venous and capillary blood samples were collected at the same time. Supplementary capillary sampling was performed on two consecutive days following the first collection. Capillary TC and TG concentrations were determined with the Accutrend ${ }^{\circledR}$ Plus using two drops of blood $(15-40 \mu \mathrm{L})$ collected from different fingers, by using a lancing device (Accu-check ${ }^{\circledR}$ Softclix ${ }^{\circledR}$ Pro, Roche Diagnostics GmbH, Mannheim, Germany). The Accutrend ${ }^{\circledR}$ Plus test is a capillary serum test. It is based on the retention of blood cells by filtration via a glass fibre fleece when a drop of blood is applied to the test strip. The enzymatic reaction that takes place in the underlying zone of the strip requires an adequate oxygen supply and results in the formation of a colored oxidation product. The reflectance of the strip (measured at $660 \mathrm{~nm}$ ) is converted to concentration through a simple algorithm. The intra assay precision of Accutrend ${ }^{\circledR}$ Plus, as determined by the manufacturer, was $3.7 \%$ and $3.4 \%$ for TC and TG respectively. The inter-assay precision for Accutrend ${ }^{\circledR}$ Plus determined with control solution by the manufacturer was lower than $5.0 \%$ for TC and $2.4 \%$ for TG [20].

\subsubsection{Hematocrit and Hemoglobin}

The Mission ${ }^{\circledR}$ Plus Hemoglobin (HGB) and Hematocrit (HCT) Testing System (ACON Laboratories, Inc., San Diego, CA, USA) are for the quantitative determination of hemoglobin and hematocrit in non-anticoagulated capillary whole blood or anticoagulated venous whole blood in EDTA (K2, K3, Na2) or sodium heparin. The testing system is designed for point-of-care use in primary care settings. Estimation of hematocrit is only for hemoglobin values from 12.3 to $17.5 \mathrm{~g} / \mathrm{dL}$ (123 to $175 \mathrm{~g} / \mathrm{L}$ ). The Mission ${ }^{\circledR}$ Plus hemoglobin and hematocrit Control Solution is intended to validate hemoglobin and hematocrit testing using the Mission ${ }^{\circledR}$ Plus Hemoglobin $(\mathrm{Hb})$ Testing System. Mission ${ }^{\circledR}$ Plus Hemoglobin and Hematocrit Testing System is for professional in vitro diagnostic use only.

\subsection{Statistical Analyses}

Means and standard deviations are given as descriptive statistics and the relationship among the relationship between healthy lifestyle behaviors, physical fitness, and coronary risk factors were 
evaluated by Pearson Product Moment Correlation analysis. All analyses were executed in SPSS for Windows version 21.0 and the statistical significance was set at $p<0.05$.

\section{Results}

Body composition, physical fitness characteristics, the healthy lifestyle behaviors, and coronary risk factors of university students are displayed in Tables 1-3 respectively.

Table 1. Body composition values of university students.

\begin{tabular}{cccccc}
\hline & Age (Year) & Height (cm) & Body Weight (kg) & Fat (\%) & BMI (kg/m $\mathbf{~}^{\mathbf{2}}$ \\
\hline Female (n: 149) & $20.37 \pm 1.53$ & $162.18 \pm 5.56$ & $58.15 \pm 8.99$ & $24.31 \pm 6.15$ & $22.08 \pm 3.18$ \\
Male (n: 171) & $21.53 \pm 3.00$ & $175.16 \pm 18.66$ & $78.29 \pm 16.30$ & $16.35 \pm 5.35$ & $24.86 \pm 5.56$ \\
Male and Female (n: 320) & $20.89 \pm 2.37$ & $168.04 \pm 14.76$ & $67.22 \pm 16.25$ & $20.66 \pm 7.01$ & $23.34 \pm 4.61$ \\
\hline
\end{tabular}

Descriptive characteristics of the subjects across body composition are shown in Table 1. According to this table, the highest rate was reached in \% fat for female and the lowest rate in male university students. Results indicated that the subjects have normal body mass index, but high body fat percentage.

Table 2 indicates the average values of physical fitness characteristics of the university students proved that the students had good physical fitness performance. As expected, male students had better scores when compared to the female students in all parameters listed.

According to Table 3, the mean values for HR, SBP, DBP, TG, TC, HGB, and HCT were in the normal range for both male and female students. In agreement with national and international literature, the data from the present study shows a considerable prevalence of cardiovascular risk factors among young adults. A family history of chronic diseases was reported by many of the university students. Several studies have revealed a greater prevalence of cardio vascular risk factors in relatives of individuals with cardiovascular diseases and type 2 diabetes mellitus when compared with those without family history of these diseases.

Table 4 shows the healthy lifestyle behaviors of the university students. According to this table, the highest rate was reached in self-actualization sub-scale, and the lowest rate in exercise. This finding depicts the contradictory attitude of university students towards exercise.

As seen in Table 5, Results of Pearson's Product Moment Correlation Analyses indicated significant positive correlations between physical fitness and coronary risk factors of university students in the present study $(p<0.05)$. The findings of this study indicated that physical fitness was an indicator of coronary risk factors of university students.

Correlations between physical fitness and coronary risk factors separately for male and female university students are also presented in Tables 6 and 7.

Correlations between physical fitness and coronary risk factors of university students are presented in Table 5.

As seen in Table 6, results of Pearson's Product Moment Correlation Analyses indicated significant positive correlations between physical fitness and coronary risk factors of male university students $(p<0.05)$. The findings of the present study indicated that physical fitness was an indicator of coronary risk factors of male university students.

As seen in Table 7, results of Pearson's Product Moment Correlation Analyses indicated significant positive correlations between physical fitness and coronary risk factors of female university students in the study subjects $(p<0.05)$. The findings of the present study indicated that physical fitness was an indicator of coronary risk factors of female university students in the Bartin University of Turkey.

Correlations between the healthy lifestyle behaviors and coronary risk factors of male and female university students are presented in Tables 8 and 9 . 
Table 2. Physical fitness characteristics values of university students.

\begin{tabular}{|c|c|c|c|c|c|c|c|c|c|}
\hline & BS (kg) & KS (kg) & RGS (kg) & LGS (kg) & $\mathrm{F}(\mathrm{cm})$ & TS (Repeat) & $10 \mathrm{~m}(\mathrm{~s})$ & $20 \mathrm{~m}(\mathrm{~s})$ & $30 \mathrm{~m}(\mathrm{~s})$ \\
\hline Female (n: 149) & $45.19 \pm 6.52$ & $44.70 \pm 28.33$ & $30.27 \pm 5.96$ & $28.18 \pm 4.29$ & $17.91 \pm 8.49$ & $20.58 \pm 7.29$ & $2.57 \pm 0.28$ & $3.83 \pm 0.32$ & $5.25 \pm 0.43$ \\
\hline Male (n: 171) & $110.84 \pm 106.9$ & $103.03 \pm 35.67$ & $44.81 \pm 7.85$ & $42.15 \pm 6.97$ & $21.67 \pm 10.29$ & $32.26 \pm 9.76$ & $2.14 \pm 0.29$ & $3.31 \pm 0.29$ & $4.55 \pm 0.43$ \\
\hline Male and Female (n: 320) & $79.95 \pm 87.13$ & $75.51 \pm 43.92$ & $39.13 \pm 10.21$ & $36.67 \pm 9.27$ & $20.42 \pm 9.81$ & $26.80 \pm 10.53$ & $2.38 \pm 0.35$ & $3.69 \pm 0.41$ & $5.02 \pm 0.55$ \\
\hline
\end{tabular}

Table 3. Coronary risk factors values of university students.

\begin{tabular}{|c|c|c|c|c|c|c|c|}
\hline & Heart Rate (Rest) (Beats per min) & SBP (mm Hg) & DBP (mm Hg) & TG (mg) & TC (mg/dL) & HGB (g/dL) & НCT (\%) \\
\hline Female (n: 149) & $84.13 \pm 10.72$ & $112.87 \pm 13.11$ & $73.45 \pm 11.81$ & $101.3 \pm 63.9$ & $173.96 \pm 32.29$ & $12.99 \pm 0.77$ & $42.17 \pm 5.68$ \\
\hline Male (n: 171) & $91.30 \pm 10.85$ & $127.53 \pm 11.70$ & $78.66 \pm 8.33$ & $70.6 \pm 38.2$ & $173.31 \pm 33.20$ & $14.73 \pm 0.97$ & $48.83 \pm 7.36$ \\
\hline Male and Female (n: 320) & $87.97 \pm 11.43$ & $120.61 \pm 14.49$ & $76.10 \pm 10.44$ & $85.9 \pm 51.05$ & $173.62 \pm 32.72$ & $13.89 \pm 1.23$ & $46.62 \pm 7.53$ \\
\hline
\end{tabular}


Table 4. Mean and standard deviation of scores of the healthy lifestyle behavior among the study participants.

\begin{tabular}{cccc}
\hline & Male and Female (n: 320) & Female (n: 149) & Male (n: 171) \\
\hline Self-actualization & $38.45 \pm 7.10$ & $36.02 \pm 5.99$ & $40.51 \pm 7.33$ \\
Health responsibility & $23.89 \pm 7.17$ & $21.10 \pm 6.53$ & $26.29 \pm 6.85$ \\
Exercise & $10.56 \pm 4.05$ & $10.25 \pm 4.03$ & $10.82 \pm 4.06$ \\
Nutrition & $17.66 \pm 3.66$ & $15.50 \pm 2.86$ & $19.52 \pm 3.05$ \\
Interpersonal support & $21.11 \pm 3.65$ & $20.07 \pm 3.08$ & $22.00 \pm 3.58$ \\
Stress management & $18.63 \pm 4.42$ & $17.22 \pm 3.55$ & $19.85 \pm 4.75$ \\
Total score of the healthy and lifestyle behavior & $130.36 \pm 24.55$ & $119.78 \pm 20.54$ & $139.12 \pm 24.22$ \\
\hline
\end{tabular}

Table 5. Correlations between physical fitness and coronary risk factors of university students.

\begin{tabular}{|c|c|c|c|c|c|c|c|c|c|}
\hline & BS & KS & F & TS & RPS & LPS & $10 \mathrm{~m}$ & $20 \mathrm{~m}$ & $30 \mathrm{~m}$ \\
\hline HR & $0.244^{* *}$ & $0.430^{* *}$ & $0.409^{* *}$ & $0.178^{* *}$ & $0.202^{* *}$ & $0.195^{* *}$ & $-0.277^{* *}$ & $-0.408^{* *}$ & $-0.426^{* *}$ \\
\hline SBP & $0.171^{* *}$ & $0.363^{* *}$ & 0.130 * & $0.265^{* *}$ & $0.403^{* *}$ & $0.421^{* *}$ & $-0.296^{* *}$ & $-0.387^{* *}$ & $-0.340^{* *}$ \\
\hline DBP & NS & $0.160^{* *}$ & NS & 0.151 * & $0.246^{* *}$ & $0.254^{* *}$ & $-0.175^{*}$ & NS & NS \\
\hline TG & NS & $0.261^{* *}$ & NS & NS & $0.310^{* *}$ & $0.263^{* *}$ & -0.203 * & $-0.290 * *$ & $-0.290^{* *}$ \\
\hline $\mathrm{TC}$ & NS & NS & NS & NS & NS & NS & NS & NS & NS \\
\hline HCT & 0.155 * & $0.219 * *$ & NS & $0.212 * *$ & $0.374^{* *}$ & $0.366^{* *}$ & $-0.287^{* *}$ & $-0.275^{* *}$ & -0.240 * \\
\hline HGB & $0.385^{* *}$ & $0.485^{* *}$ & NS & $0.367^{* *}$ & $0.482^{* *}$ & $0.565 * *$ & $-0.385^{* *}$ & $-0.316^{* *}$ & $-0.396^{* *}$ \\
\hline
\end{tabular}

Table 6. Correlations between physical fitness and coronary risk factors of male university students.

\begin{tabular}{cccccccccc}
\hline & BS & KS & F & TS & RPS & LPS & $\mathbf{1 0 ~} \mathbf{m}$ & $\mathbf{2 0 ~ \mathbf { ~ }}$ & $\mathbf{3 0 ~ \mathbf { ~ }}$ \\
\hline HR & $0.176^{*}$ & $0.446^{* *}$ & NS & NS & $0.495^{* *}$ & NS & NS & $-0.404^{* *}$ & $-0.345^{*}$ \\
SBP & NS & NS & NS & NS & NS & NS & NS & NS & NS \\
DBP & NS & NS & NS & NS & NS & NS & NS & NS & NS \\
TG & NS & NS & NS & NS & NS & NS & $0.326^{* *}$ & $0.316^{*}$ & NS \\
TC & NS & NS & NS & NS & NS & NS & $0.326^{* *}$ & $0.316^{*}$ & NS \\
HCT & NS & NS & NS & NS & NS & NS & NS & NS & NS \\
HGB & $0.221^{*}$ & NS & NS & NS & NS & NS & NS & NS & NS \\
\hline
\end{tabular}

Table 7. Correlations between physical fitness and coronary risk factors of female university students.

\begin{tabular}{cccccccccc}
\hline & BS & KS & F & TS & RPS & LPS & $\mathbf{1 0 ~ \mathbf { ~ }}$ & $\mathbf{2 0} \mathbf{~ m}$ & $\mathbf{3 0 ~ \mathbf { ~ }}$ \\
\hline HR & NS & NS & NS & NS & NS & NS & NS & NS & NS \\
SBP & $0.364^{* *}$ & $0.265^{* *}$ & NS & $0.219^{* *}$ & $0.380^{* *}$ & $0.401^{* *}$ & NS & NS & NS \\
DBP & NS & NS & NS & NS & $0.184^{*}$ & $0.253^{* *}$ & NS & NS & NS \\
TG & NS & NS & NS & NS & $0.319^{* *}$ & $0.337^{* *}$ & NS & NS & NS \\
TC & NS & NS & $0.171^{*}$ & NS & NS & NS & NS & NS & NS \\
HCT & NS & NS & NS & $0.193^{*}$ & $0.394^{* *}$ & $0.408^{* *}$ & NS & NS & NS \\
HGB & $0.349^{* *}$ & $0.328^{* *}$ & NS & $0.307^{* *}$ & $0.458^{* *}$ & $0.580^{* *}$ & NS & $0.228^{*}$ & NS \\
\hline \multicolumn{8}{c}{$p<0.01^{* *} p<0.05}$. \\
\end{tabular}

As seen in Table 8, results indicated significantly positive correlations between healthy lifestyle behaviors and coronary risk factors of male university students in the study subjects $(p<0.05)$. The findings of the present study indicated that healthy lifestyle behaviors were indicators of coronary risk factors of male university students in the Bartin University of Turkey.

As seen in Table 9, results indicated significantly positive correlations between healthy lifestyle behaviors and coronary risk factors of female university students in the study subjects $(p<0.05)$. The findings of the present study indicated that healthy lifestyle behaviors were an indicator of coronary risk factors of female university students in the Bartin University of Turkey. 
Table 8. Correlations between healthy lifestyle behaviors and coronary risk factors of male university students.

\begin{tabular}{|c|c|c|c|c|c|c|c|}
\hline & SA & HR & E & $\mathbf{N}$ & IS & SM & HLSB \\
\hline HR & $0.208^{* *}$ & $0.245^{* *}$ & NS & $0.355^{* *}$ & $0.265^{*}$ & $0.278^{* *}$ & $0.287^{* *}$ \\
\hline SBP & NS & NS & 0.134 * & $0.262^{* *}$ & 0.123 * & NS & NS \\
\hline DBP & NS & NS & NS & NS & NS & NS & NS \\
\hline $\mathrm{TG}$ & NS & $0.247^{* *}$ & $0.125^{* *}$ & $225^{* *}$ & $0.187^{*}$ & 0.162 * & $0.214^{* *}$ \\
\hline $\mathrm{TC}$ & NS & $0.126^{* *}$ & $0.205^{*}$ & NS & NS & NS & 0.153 * \\
\hline $\mathrm{HCT}$ & $0.128 *$ & $248^{* *}$ & $0.297 *$ & $293^{* *}$ & 0.189 * & $0.176^{*}$ & 0.234 * \\
\hline HGB & $0.248^{* *}$ & $0.282 * *$ & $0.239 * *$ & $369 * *$ & $0.215^{*}$ & $0.232^{* *}$ & 0.258 * \\
\hline
\end{tabular}

Table 9. Correlations between healthy lifestyle behaviors and coronary risk factors of female university students.

\begin{tabular}{|c|c|c|c|c|c|c|c|}
\hline & SA & HR & E & $\mathbf{N}$ & IS & SM & HLSB \\
\hline HR & $0.210^{* *}$ & $0.203^{* *}$ & NS & $0.334^{* *}$ & 0.214 * & $0.267^{* *}$ & $0.275^{* *}$ \\
\hline SBP & NS & NS & $0.145^{*}$ & $0.245^{* *}$ & 0.153 * & NS & NS \\
\hline DBP & NS & NS & NS & NS & NS & NS & NS \\
\hline $\mathrm{TG}$ & 0.102 * & $0.252 * *$ & $0.152 * *$ & $227^{* *}$ & 0.179 * & 0.141 * & $0.206^{* *}$ \\
\hline $\mathrm{TC}$ & NS & NS & 0.148 * & NS & NS & NS & NS \\
\hline $\mathrm{HCT}$ & 0.149 * & $256^{* *}$ & 0.298 * & $289^{* *}$ & 0.176 * & $0.149 *$ & $0.211^{* *}$ \\
\hline HGB & 0.217 * & $0.276^{* *}$ & $0.248^{* *}$ & $387^{* *}$ & $0.146^{*}$ & $0.228^{* *}$ & $0.295^{* *}$ \\
\hline
\end{tabular}

\section{Discussion}

The findings of the present study indicated that physical fitness plays a determinant role in coronary heart disease risk factors for male and female students from a university. In addition, PAL was found to be an important factor in coronary heart disease risk factors of university students. Coronary heart disease risk factors (CHDRF) included mean arterial blood pressure (systolic (SBP) and diastolic (DBP)), fasting blood levels of triglycerides (TG), low-density lipoprotein cholesterol (LDL-C), high-density lipoprotein cholesterol (HDL-C) and total cholesterol (TC) in this present study [1]. Further, the pattern of loadings in boys and girls remarkably similar in this sample (Table 3) suggesting that sex differences in the relationship between PAL and CHDRF are small if they exist. And also the findings of the present study are consistent with previous studies that have demonstrated relationships between PAL and CHDRF, particularly for blood lipids [3,12]. Although physical fitness (PF) was the best predictor of SBP, DBP, TG, LDL-C, HDL-C, and TC, while PAL were not shown to be significant predictors. The result indicate that $\mathrm{F}, \mathrm{KS}, \mathrm{BS}, \mathrm{TS}, \mathrm{VO}_{2 \max }, \mathrm{BMI}$, and $\%$ fat are important determinants of CHDRF in university students, with PF exhibiting a slightly stronger relationship than PAL. However, this result must be tempered by the limitations of the study. Although physical record used is a reliable measure of habitual activity levels, the error associated with the indicators of physical activity is undoubtedly greater than error associated with the measurements of PF [3]. Another explanation for the greater relationship between fitness and CHDRF may be genetics. Perhaps genes which are influencing physical fitness also influence CHDRF (genetic pleiotropy) [3]. Eisenmann et al. [11] reported that a significant relationship between adolescent cardiorespiratory fitness and adult body fatness and a lack of an association between adolescent cardiorespiratory fitness and adult cholesterol, blood pressure, and glucose levels. Adolescent body fatness is moderately related to selected adult $\mathrm{CHDRF}$ and this could be influencing the pattern of loading for $\mathrm{PF}$, independent of chronological age [3].

Sprint performance and strength is fundamental activity for many sports and also sports performance is the outcome of several variables, including physical fitness. Differentiated physical 
fitness profiles might, therefore, be considered as a parameter of sports-specific demands, and as such contribute to an enhanced knowledge of the level of performance [21].

Considering that some of the cardiovascular risk factors are modifiable by changes in lifestyle, educational programs aimed at motivating the adoption of healthy lifestyle choices would be helpful, especially in upcoming health care professionals, as it is them who will be taking care of the health of the population in the future [22].

\section{Conclusions}

To sum up, an important prevalence of cardiovascular risk factors was observed in the university students included in the present study which has not been pointed out in Turkish literature up to date. Besides, the study clearly conveyed that there is a positive correlation between healthy lifestyle behaviors, physical fitness, and cardiovascular risk factors of the students. Therefore, further studies should be carried on similar samples in order to define the main causes of cardiovascular risk factors and to create awareness on the importance of physical fitness and healthy lifestyle behaviors to avoid these kinds of risk factors.

Acknowledgments: This study was approved by Bartin University Institutional Review Board, Ethics Committee and supported by Bartin University Scientific Research Projects Commission (Project No: 2016-SOS-A-006).

Author Contributions: Ali Ozkan was the primary one shaping the main text and Mutlu Turkmen formatted the last version of the text in English. All the other authors contributed to the article equally in gathering data, scanning the literature, formatting the research, and finally revising the text.

Conflicts of Interest: The authors declare no conflict of interest.

\section{References}

1. Wilson, P.W.F.; Agostino, R.B.D.; Levy, D.; Belander, A.M.; Silbershatz, H.; Kannel, W.B. Prediction of coronary heart Disease Using Risk Factor Categories. Circulation 1998, 97, 1837-1847. [CrossRef] [PubMed]

2. Knight, S.; Bermingham, M.A.; Mahajan, D. Regular non-vigorous physical activity and cholesterol levels in the elderly. Gerontology 1999, 45, 213-219. [CrossRef] [PubMed]

3. Katzmarzyk, P.T.; Malina, R.M.; Bouchard, C. Physical activity, physical fitness, and Coronary heart disease risk factors in youth: The Quebec family study. Prev. Med. 1999, 29, 555-562. [CrossRef] [PubMed]

4. Flack, J.; Yunis, C. Therapeutic implications of the epidemiology and timming of myocardial infarction and other cardiovascular diseases. J. Hum. Hypertens. 1997, 11, 23-28. [CrossRef] [PubMed]

5. Onat, A. Risk factors and cardiovascular disease in Turkey. Atherosclerosis 2001, 156, 1-10. [CrossRef]

6. Hokanson, J.E.; Kamboh, M.I.; Scarboro, S.; Eckel, R.H.; Hamman, R.F. Effects of the hepatic lipase gene and physical activity on coronary heart disease risk. Am. J. Epidemiol. 2003, 158, 836-843. [CrossRef] [PubMed]

7. Dusa, F.S.; Badau, A.; Badau, D.; Trambitas, C.; Brinzaniuc, K. Investigating the Deformation Parameters of PVC Fitness Balls in Relation to the Height and Body Mass Index of the Users. Mater. Plast. 2017, 54, 606-609.

8. Badau, A. Study of somatic, motor and functional effects of practicing initiation programs in water gymnastics and swimming by students of physical education and sports. Phys. Educ. Stud. 2017, 21, 158-164. [CrossRef]

9. Badau, D.; Prebeg, G.; Mitić, D.; Badau, A. Fitness index and VO2max of physical education students. Ovidius Univ. Ann. Ser. Phys. Educ. Sport Sci. Mov. Health 2015, 15, 246-251.

10. Williams, P.T. Physical fitness and activity as separate heart disease risk factors: A meta-analysis. Med. Sci. Sports Exerc. 2001, 33, 754-761. [CrossRef] [PubMed]

11. Eisenmann, J.C.; Wickel, E.E.; Welk, G.J.; Blair, S.N. Relationship between adolescent fitness and fatness and cardiovascular disease risk factors in adulthood: The aerobics center longitudinal study (ACLS). Am. Heart J. 2005, 149, 46-53. [CrossRef] [PubMed]

12. Raitakari, O.T.; Taimela, S.; Porkka, K.V.K.; Telema, R.; Valimaki, I.; Akerblom, H.K.; Viikari, J.S.A. Associations between physical activity and risk factors for coronary heart disease: The Cardiovascular Risk in Young Finns Study. Med. Sci. Sports Exerc. 1997, 29, 1055-1061. [CrossRef] [PubMed] 
13. Sörensen, L.E.; Pekkonen, M.M.; Mannikkö, K.H.; Louhevaara, V.A.; Smolander, J.; Alen, M.J. Associations between work ability, health-related quality of life, physical activity and fitness among middle-aged men. Appl. Ergon. 2008, 39, 786-791. [CrossRef] [PubMed]

14. Klasson-Heggebo, L.; Andersen, L.B.; Wennlöf, A.H.; Sardinha, L.B.; Harro, M.; Froberg, K.; Anderssen, S.A. Graded associationship between cardiorespiratory fitness, fatness and blood pressure in children and adolescents. Br. J. Sports Med. 2006, 40, 25-29. [CrossRef] [PubMed]

15. Lohman, T.G.; Slaughter, M.H.; Boileau, R.A.; Bunt, J.; Lussier, L. Bone mineral measurements and their relation to body density in children, youth, and adults. Hum. Biol. 1984, 56, 667-679. [PubMed]

16. Walker, S.N.; Sechrist, K.R.; Pender, N.J. The health-promoting lifestyle profile: Development and psychometric characteristics. Nurs. Res. 1987, 36, 76-81. [CrossRef] [PubMed]

17. Esin, M.N. Evaluation and Promotion of Health Behaviors of Industry Workers. Ph.D. Thesis, Istanbul University Health Science Institute, Istanbul, Turkey, 1997, unpublished. (In Turkish)

18. Akca, S. Evaluation of Health Behaviors among Lecturers and of Affecting Factors. Ph.D. Thesis, Ege University Health Science Institute, Izmir, Turkey, 1998, unpublished. (In Turkish)

19. Kayıhan, G.; Ersöz, G.; Özkan, A. The relationship between selected physical-physiological parameters and efficiency of pistol shooting. Policing Int. J. Police Strateg. Manag. 2013, 36, 819-832. [CrossRef]

20. Scafoglieri, A.; Tresignie, J.; Provyn, S.; Clarys, J.P.; Bautmans, I. Reproducibility, accuracy, and concordance of Accutrend ${ }^{\circledR}$ Plus for measuring circulating lipid concentration in adults. Biochem. Med. Biochem. Med. 2012, 22, 100-108. [CrossRef]

21. Van de Vliet, P.; Rintala, P.; Fröjd, K.; Verellen, J.; Van Houtte, S.; Daly, D.J.; Vanlandewijck, Y.C. Physical fitness profile of elite athletes with intellectual disability. Scand. J. Med. Sci. Sports 2006, 16, 417-425. [CrossRef] [PubMed]

22. Costa Silva Zemdegs, J.; Barreto Corsi, L.; De Castro Coelho, L.; Duarte Pimentel, G.; Toyomi Hirai, A.; Sachs, A. Lipid profile and cardiovascular risk factors among first-year Brazilian university students in São Paulo. Nutr. Hosp. 2011, 26, 553-559. [CrossRef] [PubMed]

(C) 2018 by the authors. Licensee MDPI, Basel, Switzerland. This article is an open access article distributed under the terms and conditions of the Creative Commons Attribution (CC BY) license (http:/ / creativecommons.org/licenses/by/4.0/). 